УДК $78.01+788.2$

\title{
Цзоу Вей
}

\section{НОВЫЕ ПРЕДПОСЫЛКИ ИНТЕРПРЕТАЦИИ ТЕМБРА ТРОМБОНА В МУЗЫКЕ ВТОРОЙ ПОЛОВИНЫ ХХ - НАЧАЛА ХХІ ВЕКА}

Статья посвящена актуальным вопросам формирования специфических черт тембра тромбона в современной музыке. Рассматриваются этапы становления тромбонового репертуара в XX- начале XXI века. Анализируются новые тембровые, мелодические и драматургические возможности инструмента на примере творчества современных композиторов.

Ключевые слова: музыка для тромбона, тембр, звук, эволюция тромбона, исполнительское искусство.

В музыке XX века происходит кардинальное переосмысление основополагающих элементов музыкальной речи. Возрастающая роль тембра в иерархии звуковых выразительных средств становится все более очевидной. Он становится одним из самых существенных компонентов музыкальной системы XX века, выступает в совершенно новом качестве - специфического музыкального средства, а также способен выполнять самостоятельно содержательные и конструктивно-организующие функции. Как пишет В. Холопова: «Специфику формообразования новаторского композиторского творчества второй половины XX века составила полипараметровость, многоуровневость и полная индивидуализация музыкальной композиции. Полипараметровость означает, что действуют... не те две формообразующие основы, что в классической форме... а иные... и качественно большее их число. Еще в музыке первой половины века в качестве ведущих основ стали выступать ритмика и мелодическая линеарность. Во второй половине к ним прибавились фактура, тембр... «параметр экспрессии», пространственность ... и другие» [6, с. 445-446]. Таким образом, тембр сейчас, наряду с гармонией, ритмикой, фактурой, осознается не только как мощный формообразующий, но зачастую и темообразующий, а нередко и стилеобразующий фактор.

Динамичное развитие системы музыкальных средств в искусстве $\mathrm{XX}$ века обусловило появление художественных направлений, основанных на новом слышании звука. Сонористика (К. Пендерецкий, К. Сероцкий, А. Добровольский, В. Котоньский, Х. Гурецкий), алеа- 
торика (В. Лютославский), стохастика (Я. Ксенакис), электронная и «конкретная» музыка выдвигают на первый план звуковую красочность. Одна из ветвей сонорной музыки связана с шумовой звучностью - экспериментальным открытием представителей музыкального футуризма (Л. Руссоло, Ф. Прателла), другая - с окраской отдельных звуков-точек в сериальной ткани и пуантилизме (А. Веберн, П. Булез, К. Штокхаузен) [7]. В сочинениях такого рода проблематика тембра возводится в ряд важнейших тем в создаваемой теории современного музыкального языка. Кроме того, темброколорит (термин М. Манафовой) в них зачастую выступает как своего рода концепция: он нередко является отправным моментом на концептуальном уровне, стимулирующим возникновение творческих идей, реализуемых композитором в оркестровом письме.

Процессы переосмысления традиционной системы выразительных средств музыки идут в XX веке, как и ранее, параллельно и во взаимной связи с обновлением / усовершенствованием в сфере инструментария и в области исполнительской техники. Несмотря на то, что тромбон в своей эволюции претерпел значительно меньшие изменения в конструкции по сравнению, например, с трубой, последние несколько десятилетий XX века являются подлинной революцией в усовершенствовании инструмента. Весь тромбонный мир пришел к единому стандарту в мензуре (речь не идет о джазовых исполнителях). Для тенор-тромбонистов это Largebore 547, для басистов - ExtraLargebore 562. В конце 1980-х можно говорить о возрождении инструментов, преданных забвению: это альтовый тромбон in Es и контрабас-тромбон in F. Басовый тромбон in B во второй половине $\mathrm{XX}$ столетия оснащается двумя $\mathrm{F} / \mathrm{D}(\mathrm{G}$ бемоль) вентилями вместо одного, что несомненно добавило удобства в игре, и недосягаемая нота $\mathrm{h}$ в контроктаве теперь не является проблемой. Американский изобретатель Эд Таер предложил тромбонному миру принципиально новую модель обоих вентилей - «Axial Flow Valves», и сегодня многие фирмы пошли по пути «Thayer». Кроме хорошо известных производителей тромбонов, таких как американские «Bach», «Conn», «Holton», японская «Yаmaha», появляются новые фирмы, и они сразу же завоевывают признание исполнителей. В первую очередь это «Edwards» и «Shires» (США), в Европе новую линию тромбонов выпускает французская фирма «Courtois». За последние десятилетия вырос интерес к традиционным немецким инструментам, которые значительно отличаются от стандарта сегодняшнего дня. Сделанные 
по прежним эталонам, но с учетом современных технологий, эти инструменты используются многими оркестрами для исполнения немецкой классики [5].

Модернизация в XX веке конструкции тромбона стала стимулом для расширения приемов игры и рождения новых способов звукоизвлечения на нем. Многое из современного артикуляционноштрихового багажа тромбона своему появлению обязано как композиторским новациям, так и самим исполнителям - выдающимся тромбонистам. Так, именно к середине прошлого столетия окончательно сформировались самобытные национальные школы в Америке и ряде стран Европы.

Причины восстановления композиторской интереса к музыке для тромбона после затишья в конце XIX и первых десятилетиях XX века были связаны, с одной стороны, с растущей популярностью духовых инструментов, а с другой, с огромным прорывом в исполнительской школе, что способствовало появлению выдающихся артистов - виртуозов игры на духовых инструментах. Благодаря стремительному росту исполнительского мастерства и выдающимся личным заслугам тромбонистов, таких как А. Скобелев, В. Блажевич, В. Назаров, М. Пиганов, В. Сумеркин, Ремингтон Эмори, Пауль Вешке и других, тромбон уверенно завоевывает статус сольного концертного инструмента, демонстрируя процессы существенного видоизменения тембровых реалий звучания.

Сольный репертуар для духовых инструментов в первой половине XX века был весьма ограниченным, он содержал в основном переложения для медных духовых инструментов произведений, написанных для вокалистов или других инструментов. Инструктивный и художественный материал составляли произведения Ж. Арбан, В. Брандта, О. Беме, В. Вурма, направленные на совершенствование исполнительской выразительности и виртуозности, однако не имевшие образного и драматического развития. Над созданием тромбонного репертуара преимущественно работали В. Блажевич и Е. Рейхе.

Потребности исполнителей удовлетворялись за счет старого концертного репертуара, а также камерно-инструментальных и ансамблевых произведений молодых авторов. Дефицит концертных произведений для тромбона заставлял талантливых исполнителейтромбонистов периодически выступать в роли композиторов - со стремлением расширить свой концертный репертуар. Ярким подтверждением чему стало творчества В. Блажевича. Передовые для 
первой половины XX века по использованию технических, звуковых, тесситурных возможностей тромбона произведения В. Блажевича стали «революционными», сделав настоящий переворот в мировой литературе для медных духовых инструментов. Эти произведения сыграли положительную роль в историческом процессе развития музыки для тромбона. Для них характерна тесная связь с традициями русской и зарубежной музыки второй половины XIX - начала XX века. В целом этим произведениям присущи нормы классического мелодизма, функциональные гармонии и традиционное построение музыкальной формы.

В первой половине XX века также возрастает роль тромбона как оркестрового инструмента, чему в немалой степени поспособствовало творчество Г. Малера, Г. Штрауса, П. Хиндемита и особенно И. Стравинского. Большое влияние на духовое исполнительство этого периода оказал джаз. В 1940-1950-х годах тромбоновый репертуар обогащается произведениями французских композиторов Д. Мийо и А. Томази. Отечественная музыка для тромбона пополняется сочинениями В. Успенского, Е. Мирзояна, которые продолжили традиции С. Прокофьева и Д. Шостаковича. Художественный метод этих авторов, не стилизация в духе упомянутых композиторов, а «внутренне содержательное родство с методом их мышления на основе общности художественно-выразительных сфер (таких, как разработка философских и эстетических идей, динамика общего развития музыкальной драматургии, ясность мелодизма, экспрессия лирических образов)» [2, с. 13].

Лишь во второй половине XX века музыка для тромбона находит свой собственный путь развития, подтверждением чему служат появившиеся в этот период произведения для тромбона западноевропейских и отечественных композиторов - К. Сероцкого, Е. Блоха, Х. Генцмера, Я. Ксенакиса, Б. Горбульскиса, Г. Фрида, Э. Денисова и А. Шнитке. В целом для всех произведений этого периода характерна экспериментальность, обусловленная стремлением к радикальным изменениям драматургических и музыкально-выразительных средств: использование полиладовости, политональности, внедрение новых технико-композиционных систем - додекафонии, алеаторики, сонористики.

В этот период происходит дальнейший рост уровня исполнительской школы игры на духовых инструментах и тромбон становится постоянным участником престижных международных конкурсов. 
Усилиями ведущих мировых исполнителей тромбон, в качестве солирующего инструмента, появляется в Carnegie Hall, в большом («караяновском») зале Берлинской филармонии. И даже бас-тромбон обретает самостоятельную концертную жизнь.

Таким образом, на протяжении значительного по своей протяженности исторического периода второй половины XX - начала XXI века со всей очевидностью прослеживается линия возрастания интереса композиторов к тромбону, причем не только как к инструменту оркестровому, но и как к сольному. За всю многовековую историю инструмента для тромбона не было написано столько сольной и ансамблевой литературы, сколько за последние полвека.

Современные произведения для тромбона различных жанров (сонаты, поэмы, концерты, симфонии с тромбоновым solo, а также ансамблевые опусы) отражают, прежде всего, сложные индивидуально-стилистические поиски в области обновления средств и приемов тембровой выразительности, которые нуждаются в особом изучении. Эволюция тромбонового тембра во второй половине XX века в целом была направлена от драматико-трагической трактовки инструмента (сочинения для тромбона А. Шнитке, В. Гомоляки, Л. Колодуба, В. Пацеры и других) в сторону углубления психологической направленности художественных образов, лирико-философского размышления, активизации музыкально-ассоциативного ряда (Е. Зубцов, А. Рощенко, С. Губайдулиной). Постепенно расширялась тембровосемантическая палитра звуковых возможностей тромбона, появлялись оригинальные приемы музыкальной выразительности, возникали новые виртуозно-технические требования к исполнительскому мастерству.

В XX столетии на уровне средств выражения наблюдаются различные проявления мелодико-интонационной логики, которую существенно дополняют темповые и динамические средства (от рp до ff), выбор разных регистров, в том числе, зачастую низкого. Велика роль артикуляции и агогики, которые «оговаривают» интонирование почти каждого звука», наделенного «экспрессией диссонанса и консонанса» (В. Холопова) [6]. Нередко в сочинениях происходит очень тонкое распределение красок внутри одной фразы: точно взвешиваются динамические оттенки, нюанс отдельных тонов. Применяются специальные знаки, определяющие характер интонирования - всевозможные условные символы для обозначения видов звукоизвлечения и приемов игры, в которых композитор подчас находит точный 
эквивалент образу. Наконец в ремарках нередко учитывается то, что ранее было в рамках исполнительской свободы.

Анализируя особенности развития собственно тромбонного репертуара, стоит отметить не только его количественное, но и жанровое обогащение, разнообразие его стилистики и тематики. Можно выделить несколько групп произведений по жанровым признакам и исполнительским составам, в частности произведения: для тромбона соло в сопровождении фортепиано, в сопровождении других инструментов (органа, маримбы, ударных и т. д.), для однородных тромбонных ансамблей (трио, квартеты тромбоны), ансамблей медных духовых инструментов с участием тромбона; смешанных камерных ансамблей с участием тромбона; концертные пьесы и произведения крупных форм (сюиты, вариационные и сонатные циклы) в сопровождении симфонического, камерного, эстрадного, духового оркестров; вокально-инструментальные и театрализованные композиции в сопровождении камерных ансамблей с участием тромбона.

Во всех перечисленных жанровых формах экспериментально апробируются варианты тромбоновой звучности как имманентной, внутренне присущей, так и включенной в систему сложных тембровых комплексов. Здесь моменты чистого эксперимента, слома традиций, постоянного поиска необычных технических средств и приемов, отрицание привычного и устоявшегося порождают принципиально новые звуковые миры тромбона, которые значительно обогащают и расширяют его инструментальные возможности.

Музыка для тромбона конца XX - начала XXI столетия отличается не только возросшим количеством, но и принципиально иным качеством. Именно в эти годы отечественными композиторами создаются многие сочинения, которые входят сегодня в золотой фонд мирового музыкального наследия. Это тромбоновые произведения А. Шнитке, Э. Денисова, С. Губайдулиной, А. Эшпая, Р. Щедрина, А. Красотова, К. Цепколенко, В. Полевого, Е. Зубцова и других авторов. Они знаменуют переход к более сложной тематике музыкального языка, базирующейся на звукописи, звукосимволизме, тембровой многоликости инструмента. Этими композиторами были созданы произведения, которые во многом разрушают стереотипы восприятия тромбоновой звучности. Причем это относится как к ансамблевым, так и к сольным сочинениям.

Художественно-образное мышление композиторов в XX веке, возникновение новых музыкальных жанров и стилевых направле- 
ний привели к обновлению техники композиторского письма с использованием микроинтервалики, сонористики, алеаторики и др. Это сказалось на характере сольных партий тромбона, в которых для создания принципиально иной интонационной сферы стало необходимым применение нетрадиционных приемов игры на инструменте, специфических способов звукоизвлечения, которые не связаны с естественными особенностями тромбона. Характерным в современном исполнительстве стало использование крайних регистров тромбона - как верхнего, так и нижнего, с устойчивой тенденцией к расширению. Сольные партии в музыке для тромбона имеют и всегда будут иметь дискретный характер, что обусловлено особенностями сольного концертирования на медных духовых инструментах, где исполнителю необходимо создать условия для отдыха (большая физическая нагрузка), особенно после игры в высоком регистре. Постоянный (облигатный) тип сольной партии встречается очень редко.

Формирование нового взгляда на колористические возможности инструмента способствовало интенсивному развитию эстетики звука, который в XX веке вырос до значения элемента, соучаствующего в создании целого круга образов и зависящего напрямую от выбора исполнительских средств, способов трактовки тембра. Музыкальная эстетика второй половины XX века требует от инструментального звука предельной тембральной выразительности и технологической детерминации в способах достижения различных колористических эффектов. На решение проблемы создания яркого и выразительного звука сегодня нацелены устремления и исполнителей, и композиторов, и инструментальных мастеров. Повышение эстетической и художественной значимости тембровой окраски звука в системе средств музыкальной выразительности - основная тенденция, характеризующая современное музыкальное мышление.

Рост технической сложности партии тромбона, расширение границ рабочего диапазона инструмента, создание разнообразия его динамических и тембральних качеств привели к расцвету сольного тромбонового исполнительства в последней трети XX - начале XXI столетия. Современные приемы игры на тромбоне, «расцвеченные» определенными штрихами, средствами агогики и артикуляции, значительно расширили диапазон исполнительских средств тромбониста и, хотя многие из этих приемов до сих пор встречаются лишь в качестве экспериментальных и еще не завоевали широкого признания, активно вошли в арсенал современной композиторской поэтики. 
Таким образом, в течение прошлого столетия тромбон совершил стремительную эволюцию. Усложнилась конструкция, значительно расширился репертуар, возрос уровень исполнительского мастерства, сложилась система обучения, основанная на лучших достижениях классического музыкального образования. Интерес, проявленный к тромбону на рубеже XX-XXI веков, отразил ведущие тенденции современного музыкального искусства. Это, прежде всего, особое внимание к тембровой стороне звучания. Отсюда поиски новых приемов игры на тромбоне и эксперименты с различным тембровым окружением тромбона.

\section{СПИСОК ЛИТЕРАТУРЫ}

1. Кабялис Р. Тембровая динамика в оркестровый сочинениях современных композиторов : автореф. дис. ... канд. искусствоведения : спец. 17.00.03 «Музыкальное искусство» / Р. И. Кабялис. - Вильнюс, 1989. - 18 с.

2. Крыжановский Ф. Украинский концерт для тромбона в аспекте становления и развития жанра : автореф. дис. ... канд. искусствоведения : спец. 17.00 .03 «Музыкальное искусство» / Ф. П. Крыжановский. - Одесса, 2006. $18 \mathrm{c}$.

3. Крыжановский Ф. Жанр концерта в контексте исторической эволюции исполнительства на тромбоне / Ф. Крыжановский // Мова і культура. - К. : Видавничий Дім Дмитра Бураго, 2004. - Вип. 7, т. Ш. - С. 163-170.

4. Манафова М. Темброколористические свойства оркестровой ткани в музыке второй половины XX века (на примере творчества Э. Денисова) : автореф. дис. ... канд. искусствоведения : спец. 17.00.02 «Музыкальное искусство» / М. М. Манафова. - СПб, 2011. - 23 с.

5. Сумеркин В. Тромбон / В. В. Сумеркин. - М. : Музыка, 1975. - 78 с.

6. Холопова В. Формы музыкальных произведений : учебное пособие / В. Н. Холопова. - СПб. : Лань, 1999. - 496 с.

7. Цытович В. Некоторые аспекты тембровой драматургии / В. И. Цытович // Современные вопросы музыкознания. - М. : Музыка, 1976. - С. 207237.

Цзоу Вей. Нові передумови інтерпретації тембру тромбона в музиці другої половини $X X-$ початку $X X I$ століття. Стаття присвячена актуальним питанням формування специфічних рис тембру тромбона в сучасній музиці. Розглядаються етапи становлення тромбонового репертуару в XX - на початку XXI століття. Аналізуються нові темброві, мелодичні та драматургічні можливості інструменту на прикладі творчості сучасних композиторів.

Ключові слова: музика для тромбона; тембр; звук; еволюція тромбона; виконавське мистецтво. 
Zou Wei. New interpretations of the preconditions timbre of trombone in music of the second half of $X X-$ beginning of $X X I$ century. Article is devoted to topical issues of the formation of the specific features of the timbre of trombone in modern music. The stages of formation repertoire of trombones XX-XXI centuries. Explores new timbre, melodic and dramatic possibilities of the instrument on the example of modern compositors. Indicated that interest in trombone at the turn of the XX-XXI centuries, reflected the major trends in contemporary music. This was manifested primarily in a special attention to the timbre of the sound. Hence the search for new ways of playing the trombone and experiments with different timbre environment trombone.

Keywords: music for trombone; timbre; sound; evolution trombone; performing arts.

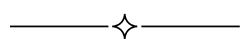

УДК 78.01/.03+786.24

\section{Ян Веньян}

\section{ТРАНСФОРМАЦИЯ ОБРАЗА ФОРТЕПИАНО В ТВОРЧЕСТВЕ ИМПРЕССИОНИСТОВ: О ТЕМБРОВО-РЕГИСТРОВЫХ КАЧЕСТВАХ ФОРТЕПИАННОЙ ИГРЫ}

Статья позволяет выделить и классифицировать те черты стиля композиторов-импрессионистов, которые привели к открытию новых приемов и способов фортепианной исполнительской интерпретации. Обсуждаются понятия фортепианной фактуры, фортепианной фактурной идеи, фортепианной звукописи, стилевой фортепианной артикуляции.

Ключевье слова: импрессионизм, фортепианная игра, интерпретация, исполнительское звукоизвлечение, звуковой образ.

Фортепианные произведения композиторов-импрессионистов открываются пониманию в контексте их поэтики как жанрово-стилевой целостности, в равной мере обращенной к «тайнам бесконечно малых и неизмеримо больших величин» (терминология Н. Герасимовой-Персидской [2]), к микрокосмосу человеческой жизни и макрокосмосу мироздания. В этом отношении их поэтика типична для круга тех проблем, с которыми связана художественная культура XX века: «...“современного” человека с небывалой силой влечет к рефлексии над сокровищами общечеловеческой культуры, и в них он находит не только радость эстетического переживания, но и созвучность эстетических идеалов... Наш бурный век... неизбежно породил тяготение к поиску постоянных, неизменных ценностей» [2, с. 33].

(C) Ян Веньян, 2014 